\title{
Does Estrogen Therapy Prevent Late Onset Alzheimer's Disease?
}

\section{Thekkuttuparambil Ananthanarayanan Ajith*}

\section{Department of Biochemistry, Amala Institute of Medical Sciences, Amala Nagar, Kerala, India}

*Corresponding Author: Thekkuttuparambil Ananthanarayanan Ajith, Professor of Biochemistry, Department of Biochemistry, Amala Institute of Medical Sciences, Amala Nagar, Kerala, India.
Received: September 29, 2020

Published: October 22, 2020

(C) All rights are reserved by Thekkuttuparambil Ananthanarayanan Ajith.
Neurodegenerative diseases such as Alzheimer's disease, Parkinson's disease, Amyotrophic lateral sclerosis and Huntington's disease remain a major challenge to human. Among the neurodegenerative diseases, Alzheimer's disease (AD) and Parkinson's disease are two major forms. According to the recent survey in US, more than 5.5 million (age 65 or older) people have dementia caused by Alzheimer's and remain the 5th leading cause of death among the elders. World Health Organization (WHO) expected $16.2 \%$ prevalence of $\mathrm{AD}$ among people over 65 years worldwide by 2050 . The median survival of AD patients who diagnosed at age 65 years is estimated to be 9 years. The disease causes $\sim 66$ $75 \%$ of household income for the management. Furthermore, due to behavioral disturbances, faecal and urinary incontinence and increase need for personal care of $\mathrm{AD}$ patients, prevalence of anxiety and depression were found among caregivers mainly female care givers. Despite large number of studies to find various mechanisms for $\mathrm{AD}$, the exact molecular mechanism in the pathophysiology of this irreversible disease has not yet been established. Formation and deposition of extracellular $\beta$-amyloid peptide $(\mathrm{A} \beta, \sim 4 \mathrm{kDa}$ protein) in an amyloidogenic pathway in the brain region leading to synaptic dysfunction, disrupting neural connectivity was demonstrated as well [1]. $A \beta$ is formed from the $\beta$-amyloid precursor protein after processing by the membranebound multi-subunit aspartyl endoprotease, $\beta$ - (exists in two forms BACE1 and BACE2) and $\gamma$-secretase. Presenilin1 or 2 (PS1 or PS2), subunit of $\gamma$ - secretase was found to be mutated in familiar AD cases. In addition to this, several forms of mutations in the $\beta$-amyloid precursor protein were also evidenced. Among the different $A \beta$ species found, the one ending at position $40(A \beta 40)$ are present in $80-90 \%$ cases, followed by slightly longer forms $A \beta 42$ in $5-10 \%$ cases. $A \beta 42$ are more toxic due to its fibrillogenic and hydrophobic nature.

Sporadic AD is a late onset disease constitutes more than $90 \%$ of the incidence in which declined activity of two metalloprotease Neprilysin and insulin-degrading enzyme (IDE) were reported. Neprilysin is for the extracellular degradation while IDE in neuronal and microglial cells is involved in both intra- and extracellu- lar degradation [2,3]. During normal aging, the activity of these two enzymes found decreased [4]. Declined mitochondrial function was found to be associated with the early onset of dementia and hence mitochondria targeted antioxidants are promising area of future research [5]. Extracellular Beta-Amyloids plaque and intracellular neurofibrillary tangles produce low-level of inflammation and oxidative stress both were found to be associated with synaptic plasticity and thus described as the hallmark of AD [6].

Women make up almost 2/3 of seniors living with Alzheimer's disease in the U.S. Episodic memory is found to be affected due to damage of the medial temporal lobe which is involved in the hippocampal formation and associated cortical areas in AD [7]. Recent studies highlighted the prophylactic role of female gonadal steroid hormones in the prevention of AD. Despite the reproductive function of gonadal hormones, they play exceptional functions on Central Nervous System. Many cellular mechanisms are triggered directly or indirectly by these hormones to enhance the brain function. Hormone replacement therapy (HRT) includes estrogen plus progestin therapy and estrogen-only therapy [8]. Among the estrogen hormones $17 \beta$-estradiol, a major estrogen hormone is mediated its action through $E R \alpha$ and $E R \beta$ receptors. Clinical and experimental studies during the last decade have evidenced several protective effect of $17 \beta$-estradiol in late onset AD.

Since $17 \beta$-estradiol can prevent the declining of reduced glutathione, a non-protein thiol in nerves the effect was considered as an antioxidant [9]. This might be effective to prevent the oxidative stress and inflammation induced by $A \beta$. Furthermore, estrogen receptors are distributed on the mitochondrial membrane and thus $17 \beta$-estradiol can prevent the accumulation of calcium via efflux of ca++ mediated by activating the $\mathrm{Na}+\mathrm{Ca}++$ exchanger on mitochondrial membrane and thus prevent the decline of mitochondrial membrane potential and apoptosis [10]. The anti-apoptotic effect can also be associated with stabilizing the bax:bcl 2 ratio in cortical neurons by increasing the level of bcl-2, an anti-apoptotic protein [11]. 17 $\beta$-estradiol can inhibit the cdk-5 and prevent the tau protein hyperphosphorylation which later forms intracellular 
neurofibrillary tangles. $17 \beta$-estradiol can increase the expression of brain derived neurotrophic factor through activation of MAPK/ ERK and PI3K signaling. Some of the neuroprotective actions of $17 \beta$-estradiol in brain are mediated ER $\beta$ than ER $\alpha$. This includes the degradation of $\beta$-amyloid by insulin dependent enzyme. The effect was found to be mediated through PI3K-AKT pathway [12]. Viña and Lloret in their review highlighted that mitochondria of young females are more protected against $\mathrm{A} \beta$ toxicity and generate less reactive oxygen species or release less apoptotic signals when compared to males or females of old age [13].

Studies in ER $\beta$ knockout mice demonstrated the significant role of $17 \beta$-estradiol in brain development. Regional neuronal hypocellularity (mainly in the cerebral cortex) and thus neuronal deficits in the brains was evidenced in ER $\beta$ knockout mice [14]. Treatment with $17 \beta$-estradiol elevated IDE in the hippocampal region and thus attenuated $A \beta$ plaque formation. This could explain the direct mechanism underlying estrogen-mediated preventative effect against $A D$ when initiated at the onset of menopause [15]. Despite the wide range of activity of $17 \beta$-estradiol against the incidence of $\mathrm{AD}$, clinical trials conducted on the protective effect remains inconclusive [16]. Study by Women's Health Initiative failed to find a protective effect. However, Henderson., et al. (2007) demonstrated that women who used hormones at younger ages had lower risks for $\mathrm{AD}$ [17]. Long term (more than 10 years) systemic (oral or transdermal) estrogen therapy was found to be protective against AD [18]. Estradiol-based hormone therapy for more than 5 years was associated with a reduced risk of mortality among Finnish women with AD [19]. However, more recent study conducted among the postmenopausal women in Finland concluded that systemic hormone therapy irrespective of hormones (estradiol or oestrogen-progestogen) was fund to be associated with a $9-17 \%$ increased risk of AD. The OR 1.09 (95\% CI 1.05 to 1.14) in estradiol treated group and OR 1.17 (\%CI 1.13 to 1.21 ) in estrogen-progestogen treated group were found [20]. Therefore, some factors are found to be associated with the beneficial effect of $17 \beta$-estradiol which includes age at the onset of therapy, dose and regimen of the hormones used, duration of therapy and risk factors associated with the incidence of AD. Nevertheless the beneficial effects of HRT in very early age of elder females, recent clinical trial data have pointed to a slight increase in the number of gynecological cancers among menopause women and prothrombotic effects which increase the risk for stroke [21]. This was found to be mediated by the peripheral estrogen receptors. The risk was found to be associated with the dose, type of medication (high concentration of estrogens or with the third-generation progestogens, cyproterone, drospirenone), age ( $>40$ years), mode of administration (oral $>$ transdermal patch and vaginal ring) and congenital or acquired predisposition to thrombosis [22]. An oral conjugated equine estrogen, the most used estrogen formulation for postmenopausal hormone therapy for the management of early menopausal symptoms among the women of age 50 - 59 years, was fund to prevent osteoporosis, cardiovascular disease and AD [23]. Hence, analogs of estrogen which act as agonist in brain and antagonist in peripheral cells are promising approach in the prophylactic therapy of AD. Thus, a long term clinical trials in middle aged women with family history of $\mathrm{AD}$ is warranted to conclude the protective effect.

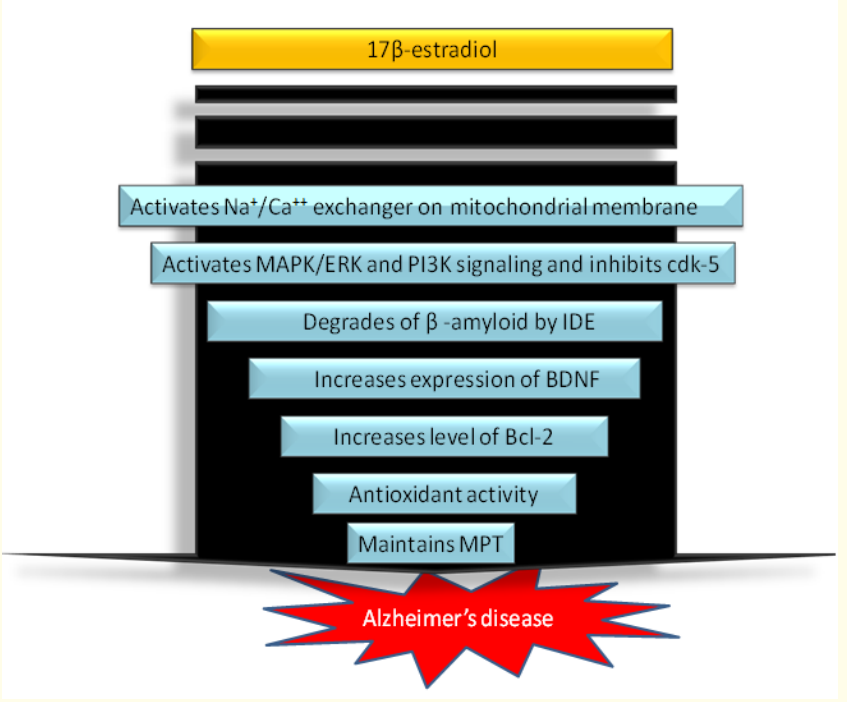

Figure 1: The various effects of $17 \beta$-estradiol on nerve cells that blocks/delays the AD. $17 \beta$-estradiol prevents the various mechanisms in the pathophysiology of Alzheimer's disease formation. It scavenges the free radical generated by neuroinflammation, scavenge free radicals in mitochondria and increases the degradation of amyloid beta to prevent plaque formation by activating insulin-degrading enzyme (IDE). Enhanced apoptosis is evidenced in $\mathrm{AD}$ brain due to the oxidative stress and neuroinflammation. $17 \beta$-estradiol decreases the apoptosis by increase calcium efflux from mitochondria by activating the $\mathrm{Na}+\mathrm{Ca}++$ exchange to maintain the mitochondrial membrane permeability transition (MPT) and increase the expression of Bcl-2, an anti-apoptotic protein on mitochondrial membrane. Furthermore, 17 $\beta$-estradiol increases the expression of Brain derived neurotrophic factor (BDNF) via PI3K/Akt signaling pathway

\section{Bibliography}

1. Murphy MP and Vine HL. "Alzheimer's Disease and the $\beta$-Amyloid Peptide". Journal of Alzheimer's Disease 19 (2010): 31.

2. Farris W., et al. "Insulin-degrading enzyme regulates the levels of insulin, amyloid beta-protein, and the beta-amyloid precursor protein intracellular domain In vivo". Proceedings of the National Academy of Sciences of the United States of America 100 (2003): 4162-4167.

3. Qiu WQ and Folstein MF. "Insulin, insulin-degrading enzyme and amyloid-beta peptide in Alzheimer's disease: review and 
hypothesis". Neurobiology of Aging 27 (2006): 190-198.

4. Caccamo A., et al. "Age- and region-dependent alterations in Abeta-degrading enzymes: implications for Abeta-induced disorders". Neurobiology of Aging 26 (2005): 645-654.

5. Ajith TA and Padmajanair G. "Mitochondrial pharmaceutics: A new therapeutic strategy to ameliorate oxidative stress in $\mathrm{Al}$ zheimer's disease". Current Aging Science 8 (2015): 235-240.

6. Stephenson J., et al. "Inflammation in CNS neurodegenerative diseases". Immunology 154 (2018): 204-219.

7. Eichenbaum H. "A cortical-Hippocampal system for declarative memory". Nature Reviews Neuroscience 1 (2000): 41-50.

8. Warren MP and Halpert S. "Hormone replacement therapy: controversies, pros and cons". Best Practice and Research Clinical Endocrinology and Metabolism 18 (2004): 317-332.

9. Prokai L., et al. "Quinol-based cyclic antioxidant mechanism in estrogen neuroprotection". Proceedings of the National Academy of Sciences of the United States of America 100 (2003): 11741-11746.

10. Petrovic S., et al. "Estradiol affects calcium transport across mitochondrial membrane in different brain regions". Annals of the New York Academy of Sciences 1048 (2005): 341-343.

11. Sribnick EA., et al. "17beta-estradiol attenuates glutamateinduced apoptosis and preserves electrophysiologic function in primary cortical neurons". Journal of Neuroscience Research 76 (2004): 688-696.

12. Zhao L., et al. "17beta-Estradiol regulates insulin-degrading enzyme expression via an ERbeta/PI3-K pathway in hippocampus: relevance to Alzheimer's prevention". Neurobiology of Aging 32 (2011): 1949-1963.

13. Viña J and Lloret A. "Why women have more Alzheimer's disease than men: gender and mitochondrial toxicity of amyloidbeta peptide". Journal of Alzheimer's Disease 20 (2010): S527S533.

14. Wang L., et al. "Estrogen receptor (ER)beta knockout mice reveal a role for ERbeta in migration of cortical neurons in the developing brain". Proceedings of the National Academy of Sciences of the United States of America 100 (2003): 703-708.

15. Zhao L., et al. "17ß-Estradiol regulates insulin-degrading enzyme expression via an ERß/PI3-K pathway in hippocampus: relevance to Alzheimer's prevention". Neurobiology of Aging 32 (2011): 1949-1963.
16. “Alzheimer's Disease and Aging: Therapeutic Potential of Estrogen". Clinical Trials Identifier NCT00066157.

17. Henderson V., et al. "Prior use of hormone therapy and incident Alzheimer's disease in the Women's Health Initiative Memory Study". The American Academy of Neurology S31 (2007): 4.

18. Imtiaz B., et al. "Risk of Alzheimer's disease among users of postmenopausal hormone therapy: A nationwide case-control study". Maturitas 98 (2017): 7-13.

19. Mikkola TS., et al. "Lower Death Risk for Vascular Dementia Than for Alzheimer's Disease With Postmenopausal Hormone Therapy Users". Metab 102 (2017): 870-877.

20. Savolainen-Peltonen H., et al. "Use of postmenopausal hormone therapy and risk of Alzheimer's disease in Finland: nationwide case-control study". British Medical Journal 364 (2019): 1665.

21. Schierbeck LL., et al. "Effect of hormone replacement therapy on cardiovascular events in recently postmenopausal women: randomised trial”. British Medical Journal 345 (2012): e6409.

22. Gialeraki A., et al. "Oral Contraceptives and HRT Risk of Thrombosis". Clinical and Applied Thrombosis/Hemostasis 24 (2018): 217-225.

23. Bhavnani BR., et al. "Pharmacology of Conjugated Equine Estrogens: Efficacy, Safety and Mechanism of Action". The Journal of Steroid Biochemistry and Molecular Biology 142 (2014): 1629.

\section{Assets from publication with us}

- Prompt Acknowledgement after receiving the article

- Thorough Double blinded peer review

- Rapid Publication

- Issue of Publication Certificate

- High visibility of your Published work

Website: www.actascientific.com/

Submit Article: www.actascientific.com/submission.php Email us: editor@actascientific.com

Contact us: +919182824667 